\title{
Aortic dissection, with rupture through ductus arteriosus into pulmonary artery
}

\author{
C. McCarthy, G. H. Dickson, E. M. M. Besterman, L. L. Bromley, and \\ A. E. Thompson ${ }^{1}$ \\ From the Department of Cardiology and Thoracic Surgery, St. Mary's Hospital, London W.2
}

A unique case of dissecting aneurysm of the aorta is presented. The dissection spread via a ductus arteriosus to the pulmonary artery and formed a re-entry window at the junction of the main and left pulmonary arteries. Cardiac catheterization and angiocardiography confirmed the presence and approximate site of the fistula. Surgery under cardiopulmonary bypass was effective in closing it. The patient remains well 18 months later.

The following is a report of a unique dissecting aneurysm. It dissected via a ductus arteriosus and main pulmonary artery with rupture into the proximal left pulmonary artery. After initial conservative treatment the ductus was transected and sutured with the aid of cardiopulmonary bypass. The outcome was successful.

Dissection of the thoracic aorta is a relatively uncommon event. Anatomically it may be divided into three types depending on the extent of aortic involvement: the entire thoracic aorta (type I), ascending (type II), or descending portion (type III) (De Bakey et al., 1965). While the results of combined medical and surgical treatment reported by Thompson et al. (1969) are encouraging, most authors consider the condition as commonly fatal (Hirst, Johns, and Kime, I958). Death may be due to rupture into the pleural or pericardial cavities or occlusion of cerebral, renal, or mesenteric vessels.

\section{Case report}

History The patient was a 54-year-old man who experienced sudden severe chest pain which radiated to the neck. It was accompanied by dyspnoea, hoarseness, and weakness of his legs.

On admission to Edgware General Hospital he was dyspnoeic, pale, and sweating. The pulse rate was I ro, collapsing in form; all peripheral pulses were present and the blood pressure was 100/40

\footnotetext{
1 Present address: Cardio-Thoracic Department, St.
} 'Thomas' Hospital, London S.E.I. $\mathrm{mm} \mathrm{Hg}$. The apex beat was hyperkinetic and displaced to the left. A continuous murmur was audible at the left sternal edge. The lower limbs were weak, flaccid, and areflectic; all sensory modalities were diminished.

Investigations The electrocardiogram was normal initially, though some ST depression in the left ventricular leads developed subsequently. Chest $x$-ray (supine) showed cardiomegaly (CT ratio $74 \%$ ), broadening of the upper mediastinum, and pulmonary plethora (Fig. I).

FIG. I Chest x-ray on admission. Supine.

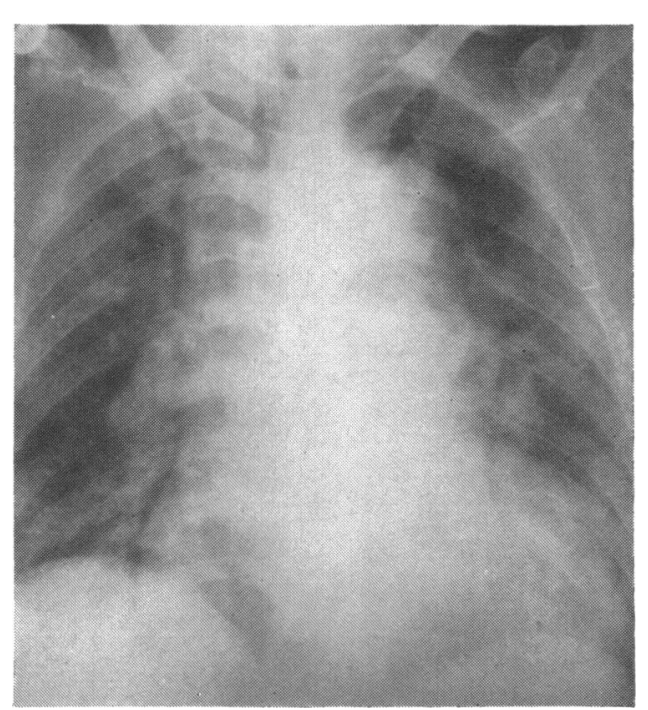


In view of these findings a diagnosis of thoracic aneurysm, probably dissecting, with aortic incompetence, or else rupture of a sinus of Valsalva was considered. It was presumed that spinal artery damage had caused the neurological signs in the legs and recurrent laryngeal nerve involvement was responsible for the hoarseness. Digoxin and diuretics were begun and hypotensive therapy instituted when the systolic blood pressure rose to $140 \mathrm{~mm} \mathrm{Hg}$. Six weeks later the patient was transferred to St. Mary's Hospital. By this time he had improved but was still slightly dyspnoeic at rest. With the exception of the murmur, which was perhaps louder, the physical signs were unchanged.

Investigations Electrocardiogram and chest $x$-ray were unchanged. Right heart catheterization: the pulmonary artery pressure was raised 95/60 (mean $67 \mathrm{mmHg}$ ). A large left-to-right shunt was localized at pulmonary artery level, the pulmonary flow being four times greater than the systemic. Aortograms via the right femoral artery showed filling of the pulmonary artery from the underside of the aortic arch. It also delineated a dissection beginning just proximal to the left subclavian artery (Fig. 2 and 3 ).

Operation was carried out on 3 June 1969.

After pressure monitoring lines were introduced, a vertical midline sternotomy was done with extension of the incision into the second left intercostal space, with wide opening of the left pleural cavity. The pericardium was opened in

FIG. 2 Aortogram. Interrupted line demarcates dissection and the dotted line the pulmonary artery.

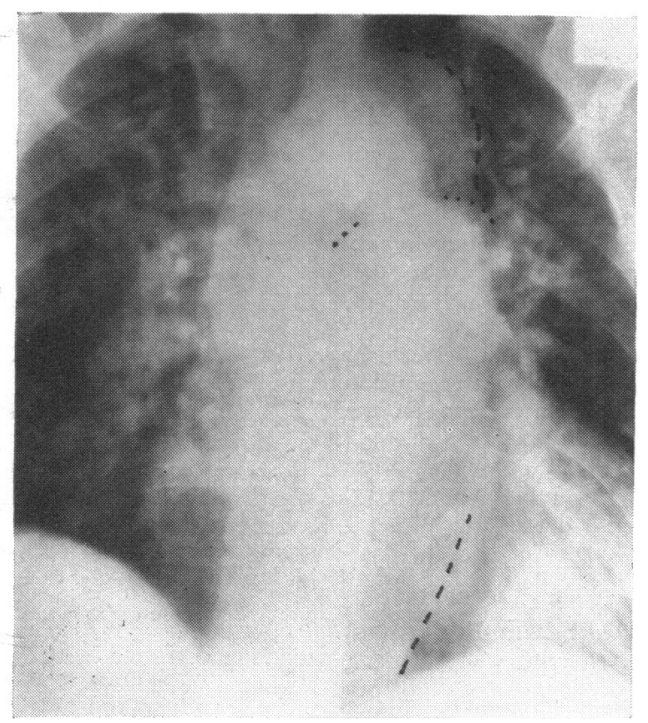

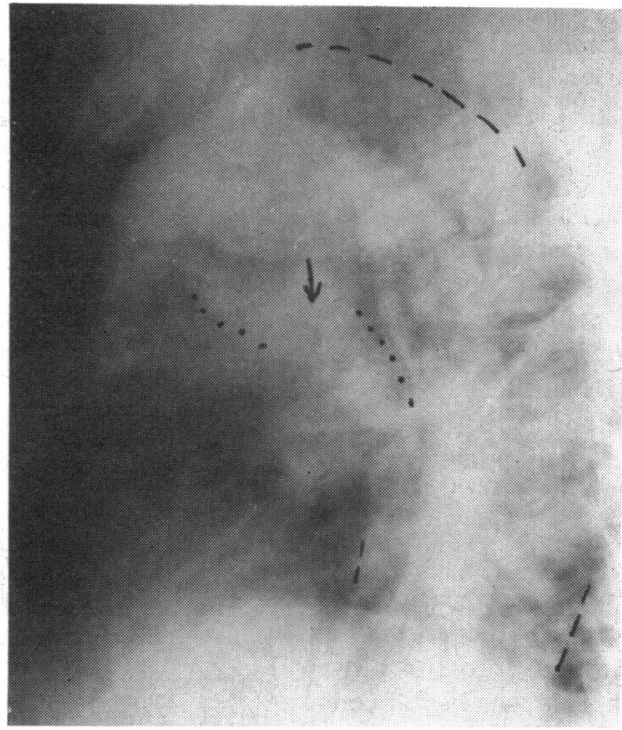

FIG. 3 Aortogram. Interrupted line demarcates dissection and the dotted line the pulmonary artery. The arrow indicates the probable site of the fistula.

the midline and reflected upwards off the great vessels. There was seen to be a type III dissecting aneurysm arising at the level of the left common carotid artery and extending downwards, at least as far as the diaphragm. The aorta was considerably dilated, and at the level of the subclavian artery was approximately $6 \mathrm{~cm}$ in diameter. The main pulmonary artery was also enlarged and there was a palpable gross continuous thrill, confirming the presence of an aortopulmonary fistula and after some local dissection it was clear that the fistula was through the ductus arteriosus region.

To facilitate dissection and in order to be able to divide the fistula and repair the pulmonary artery, cardiopulmonary bypass was instituted. The fistula was dissected out and a clamp applied across the aortic end of the shunt, with complete obliteration of the thrill. The fistula was divided and it was then apparent that the aortic dissection had extended along the ductus and burst secondarily into the main lumen of the pulmonary artery. The pulmonary artery dissection involved the distal half of the main pulmonary trunk with extensions into the proximal 2 to $3 \mathrm{~cm}$ of both right and left pulmonary arteries. There was a re-entry window $\mathrm{I} \mathrm{cm}$ in diameter into the main pulmonary trunk (Fig. 4). The aortic end of the fistula was sutured and the pulmonary artery repaired.

It was decided not to interfere with the distal aortic dissection. The heart's action being quite satisfactory, cardiopulmonary bypass was stopped and the operation completed. 
Postoperative progress was uneventful and hypotensive therapy was continued in order to reduce the risk of an extension of the aortic dissection.

\section{Discussion}

In the past, rupture of luetic aneurysms into the pulmonary artery was not an infrequent terminal event. Nicholson (1943) reviewed 8r such cases and reported 2 further instances. Since then only a dozen further cases have been reported (Ward and Kalbfleisch, 1968). These authors documented a further case which on the basis of the histological finding of medionecrosis was considered to be due to dissection of the aorta. Death occurred during attempted repair.

While Hirst et al. (1958) reviewed no less than 505 cases of dissection of the aorta, in no single instance did rupture into the pulmonary artery occur. Similarly, we have been unable to find any such case reports.

When dissection of the pulmonary artery occurs, it is usually a complication of Marfan's syndrome. However 46 cases have been documented in which dissection was secondary to atheroma, engendered by pulmonary hypertension secondary to cardiac conditions (Durno and Brown, 1908; Brenner, 1935; Israels, 1951 ; Ravines, 1960; Levy, I96I; Kapanci, 1965). In no case did a dissection spread via a ductus arteriosus or ductal remnant.

In the reported case, a normal chest $x$-ray one year previously excluded the presence of a hypertensive ductus arteriosus. However, though his cardiovascular system had been previously reported as normal, the persistence of a small patent ductus cannot be ruled out. At operation the ductus was found to be approximately $\mathrm{I} .5 \mathrm{~cm}$ in diameter. It is difficult to envisage a fibrosed ductal remnant enlarging to this dimension. Since operation the patient has been followed for 18 months and remains symptom free.

This patient is under the care of Dr. J. G. Lewis and we are indebted to him for referral and for permission to publish this report. We are indebted also to Dr. D. Sutton of the Department of Radiology, St. Mary's Hospital, for the angiographic studies.

\section{References}

Brenner, O. (1935). Pathology of the vessels of the pulmonary circulation. Archives of Internal Medicine, 56, 1189.

De Bakey, M. E., Henly, W. S., Cooley, D. A., Morris, G. C., Jr., Crawford, E. S., and Beale, A. C., Jr. (1965). Surgical management of dissecting aneurysms of the aorta. Fournal of Thoracic and Cardiovascular Surgery, 49, 130.
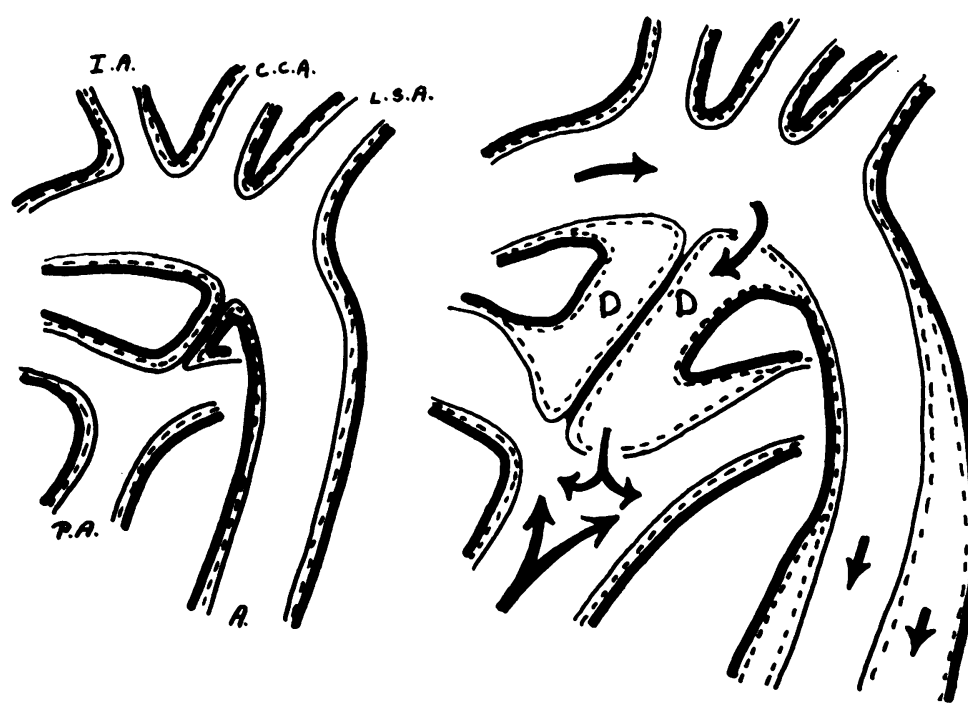

FIG. 4 Diagram of dissection. I.A. $=$ innominate artery; L.S.A. = left subclavian artery; $A .=$ aorta; $D .=$ ductus arteriosus, dissected; C.C.A. = common carotid artery; P.A. = pulmonary artery. - adventitia; ---- media; _ intima.

Durno, L., and Brown, W. L. (1908). A case of dissecting aneurysm of the pulmonary artery; patent ductus arteriosus; rupture into the pericardium. Lancet, I, 1693 .

Hirst, A. E., Johns, V. J., and Kime, S. W. (1958). Dissecting aneurysm of the aorta; a review of 505 cases. Medicine, 37, 217.

Israels, M. G. (I95I). Aneurysm of the pulmonary artery. Canadian Medical Association fournal, 64, 433.

Kapanci, Y. (1965). Médionécrose et anévrysmes disséquants des artères intra-pulmonaires. Frankfurter Zeitschrift für Pathologie, 74, 425.

Levy, H. (I961). Partial rupture of pulmonary artery with lesions of medionecrosis in a case of mitral stenosis. American Heart fournal, 62, 3r.

Nicholson, R. E. (1943). Syndrome of rupture of aortic aneurysm into the pulmonary artery; review of the literature with report of two cases. Annals of Internal Medicine, 19, 286.

Ravines, H. T. (1960). Dissecting hematomas of intrapulmonary arteries in a case of pulmonary hypertension associated with patent ductus arteriosus. fournal of Thoracic and Cardiovascular Surgery, 39, 760.

Thompson, A. E., Spracklen, F. N. H., Besterman, E. M. M., and Bromley, L. L. (1969). Recognition and management of dissecting aneurysms of the aorta. British Medical fournal, 4, 134.

Ward, R. W., and Kalbfleisch, J. H. (I968). Rupture of aortic aneurysm into the pulmonary artery. Southern Medical fournal, 61, 408.

Requests for reprints to Dr. Edwin Besterman, Department of Cardiology, St. Mary's Hospital, Praed Street, London W.2. 